\title{
A motivational perspective on the user acceptance of social media
}

\author{
A. Nelmapius and C. Boshoff* \\ Department of Business Management, University of Stellenbosch, Private Bag X1 Matieland, 7602. South Africa \\ *To whom all correspondence should be addressed \\ cboshoff@sun.ac.za
}

\begin{abstract}
Social media is a unique marketing communication medium to engage with a new generation of consumers and it has become an essential element of many organisations' strategic planning. On social media sites, consumers are engaging with and producing information, as opposed to traditional media where the marketer is in control of the media message content and information dissemination. The primary objective of this study was to investigate the intentions of users of social network sites to continue using social network sites in the future, by using a comprehensive, decomposed Theory of Planned Behaviour. The results showed that Dispositional trust, Internet self-efficacy, Psychological risk, Perceived enjoyment and Perceived usefulness exert a statistically significant influence on the intention of individuals to continue to use Facebook in the future. This study provides insights that can guide marketers' efforts to devise customised, multi-layered marketing offerings to encourage the use of social network sites for e-commerce purposes.
\end{abstract}

\section{Introduction}

The search for, locating and accessing of information in a computer-mediated environment has been strongly influenced by the Internet. The Internet and the technology that goes with it, grew so rapidly and attracted so many users in a short space of time that a whole collection of new technologies developed, including the development of the next generation web called Web 2.0. This next generation Web enabled users to communicate with one another and to contribute User-Generated Content (UGC), which led to the proliferation of social media.

The mega-platform provided by Web 2.0 can be used in a variety of ways: for creating and sharing knowledge (e.g. Wikipedia, Delicious); for innovation and collaboration (e.g. InnoCentive); for entertainment purposes (e.g. Zango, Second Life); for interaction, networking or interpersonal connection (e.g. LinkedIn, Facebook, Skype or Twitter); for designing new products and buying and selling merchandise (e.g. Ebay, Craigslist or Amazon); for connecting and communicating globally via mobile devices (e.g. Iphone, Blackberry); for reflecting via blogs (e.g. Blogger); for sharing photos (e.g. Flickr); for podcasting presentations or making creative films (e.g. YouTube); for developing projects (e.g. wikis or Google docs) and for general expression of personal ideas to the world (Karakas, 2009: 23).

However, the most popular Web 2.0 application by far, is online social networking. An online website is considered to be a 'social network site' if it offers web-based services that allow users to firstly, construct a public or semi-public profile within a bounded system and, secondly, to provide a list of other users with whom they share a connection, and thirdly, to view and traverse their list of connections and those made by others within the system (Boyd \& Ellison, 2008: 211).
Thus, social media empowers users by allowing them to share content, create content, share thoughts, share views, find information, be entertained, learn, trade and to share personal details (Baumann, 2006: 38). The popularity of social networks is evident from the fact that Facebook, the largest social network, currently has more than 1.591 billion active monthly users; 1.038 billion log onto Facebook daily; five new profiles are created every second; $91 \%$ of millennials use Facebook; $72 \%$ of all United States (US) internet users, use Facebook; $70 \%$ of the entire user base is located outside of the US and people talk to more people online than they do in real life (Smith, 2016). These user statistics substantiate the view that the use of social networks has become widely adopted among Internet users, which makes it particularly attractive to marketers as a marketing communication channel and was therefore chosen as the object of this empirical study.

Due to social networking websites' effectiveness as marketing communication channels they attract both large investors and large advertisers. For example, Microsoft bought a 1.6\% stake in Facebook at a cost of $\$ 240$ million, giving Facebook the dubious valuation of $\$ 15$ billion (Urstadt, 2008:38). Worldwide it is estimated that social networks generated $\$ 11.87$ billion in advertising dollars in 2014 (Long, 2013).

Internet technologies have grown from being one-sided and consumption-based to becoming interactive and collaborative, thus creating new opportunities for interaction between organisations and consumers.

\section{Rationale for the study}

One of the consequences of social media's empowerment of its users is that traditional media (the press, television and radio) have become much less effective and less influential as a communication medium to potential customers 
(Constantinides, 2008: 217). There is also evidence that consumers are becoming increasingly suspicious of corporate marketing efforts, with the result that the number of consumers attracted by traditional marketing and advertising media is declining. For instance, a few years ago, Constantinides (2008: 218) reported that $61 \%$ of US consumers believed that marketing and advertising was "out of control". The study found that $60 \%$ of consumers at that time had a negative attitude towards many contemporary marketing practices and advertising, while only $18 \%$ of the TV audience actually watched TV commercials.

Since then, consumers have increasingly been turning to thousands of social websites where they can interact with other consumers when searching for information and advice. This increase in social website usage is not only due to consumers' mounting mistrust of corporate communication, but also because of the weakening of their emotional connection to traditional brands (Constantinides, 2008: 218). Furthermore, consumer-generated media like weblogs, online communities, podcasts, social networks and web forums/bulletin boards make the customer more informed, educated, sophisticated and more empowered than previously. The customer can make his or her voice heard to a wider audience, giving them greater negotiating power.

This increase in collaboration among users has necessitated a fundamental change in many business models and has reshaped markets as it empowers Internet retailers (e-tailers), potential customers, current customers and consumer groups (Delayco \& Walcutt, 2010: 128). On social media sites, consumers are engaging with and producing information, which is fundamentally different from traditional media where the marketer is in control of the media message content and of information dissemination.

Marketers who have to deal with this new marketing communication context have to create a venue for conversation with the customer without appearing to control the conversation. In order to be this invisible influencer, marketers need to understand the dynamic perceptions, motivations and barriers of social network sites. Against this background user acceptance theories (Foster, Francescucci, \& West, 2010: 4) can be a valuable framework for exploring human behaviour in this computer-mediated environment.

\section{Purpose of the study}

The factors that influence the acceptance of social network sites are of interest to a large number of disciplines, including information technology, psychology and marketing. The acceptance and usage of social network sites can be conceptualised as the outcome variables of a psychological process that the user engages with when making the decision whether or not to accept and use (and continue to use) a social network site. It is important to both academic researchers and marketers to understand the determinants of the acceptance or rejection of social network sites so that methods can be developed for designing, evaluating, and predicting how users will respond to the new technology (Dillon \& Morris, 1996: 8).
Foster et al. (2010: 7) found that social network users participate in social networks to satisfy a range of different motivational needs. Therefore, to encourage acceptance social networks must offer a multi-faceted experience that will address a variety of different motivations for participation. Li (2007) proposed the concept of a multilayered perspective and coined the term 'social technographics' to describe the different ways in which consumers may behave online, based on their personality characteristics and circumstances. These 'social technographics', in turn, govern how the users will respond to approaches from marketers via social networking marketing channels.

A number of individual aspects relating to the acceptance of information technology have been examined, including cognitive style (Huber, 1983); internal beliefs and their impact on usage behaviour (Ives, Olson \& Baroudi, 1983); acceptance as a function of user involvement in systems development (Barki \& Hartwick, 1994); type of system development process used (Alavi, 1984); and the process by which technology is implemented and diffused (Brancheau, Janz \& Wetherbe, 1996). DeSanctis (1983: 247) found that no individual variable accounts for a sufficient amount of variance in the user acceptance of new technology and, therefore, it is proposed that a multi-faceted approach to acceptance be incorporated into a model in order to better explain user acceptance.

Ajzen (1991: 179) concurs with the multi-faceted view and suggests that human behaviour is complex and favours a multi-dimensional model to predict consumer behaviour. A number of authors, inter alia, Compeau and Higgins (1995:189) and Sommer (2011: 91) recommend that additional constructs be added to models predicting user acceptance. Taylor and Todd (1995: 140) wanted to explore the relationship between belief structures and its antecedent intentions, and examined ways to decompose beliefs into multi-dimensional constructs. Lin (2008: 433) believe that a decomposed Theory of Planned Behaviour is a much improved method to predict consumer intentions to shop online.

Ardichvili (2008) investigated a model of technology-use that included both motivators and de-motivators of social network use, but it was limited to a defined community of practice (i.e. knowledge sharing in virtual communities of practice). Cha (2010) identified factors affecting the use of social networking sites and focussed on the dimensions of the medium's frequency and volume of use. However, Cha (2010) did not distinguish between different types of uses in the study.

Foster et al. (2010: 4) did investigate the factors motivating participation in social network sites, as well as the barriers limiting social network site participation. The study was, however, limited to a convenience sample of 18-30 year old students from one university, and was restricted to attitudinal aspects only, rather than assessing a comprehensive model. 
There are parsimonious models exploring a subset of factors to explain the intentions to use or not to use online social network sites, but no comprehensive model exists that integrates these factors into a parsimonious model. The purpose of this study was to address this limitation.

\section{Research objective}

The primary objective of this study was to investigate social media acceptance by using a decomposed Theory of Planned Behaviour to investigate continued Facebook usage - the dependent variable in this study.

\section{Decomposed theory of planned behaviour}

A decompositional approach to theorising has a number of advantages over the one-dimensional approach. Firstly, a decomposed belief construct consists of a number of dimensions, which provides a clear understanding of specific factors that influence behaviour and secondly, a decomposed construct provides a set of beliefs which can be applied across a variety of settings (Taylor \& Todd, 1995: 140).

The decomposed Theory of Planned behaviour model used in this study includes the relevant constructs from the following models: the Theory of Reasoned Action, the Technology Acceptance Model, the Motivational Model, the Theory of Planned Behaviour, a model combining the Technology Acceptance Model and the Theory of Planned Behaviour, the Model of Personal Computer Utilisation, the innovation diffusion theory, and the Social Cognitive Theory. The purpose of this analysis of the decomposed model proposed by Lin (2008: 436) and the other user-acceptance models is to exclude the constructs that are not relevant for investigating social network usage. The resulting comprehensive, integrated and decomposed model of the Theory of Planned Behaviour is used as theoretical basis of this study.

\section{Operationalisation of model constructs}

The antecedents of the expanded decomposed Theory of Planned Behaviour (which are the independent variables in this study) include: Perceived usefulness, Perceived ease of use, Perceived enjoyment, Need to belong, Collective selfesteem, the Need for cognition, Dispositional trust, Interpersonal trust, Privacy risk, Psychological risk, Social risk, Susceptibility to norm influence and Internet selfefficacy. The model is illustrated in Figure 1 and the constructs are operationalised as follows:

\section{Perceived usefulness}

Perceived usefulness is the extent to which a user believes that his/her efficiency would improve due to the use of social media (Davis, 1989: 320).

\section{Perceived ease of use}

Perceived ease of use refers to the extent that a user believes that using social media would be effortless, both physically and mentally (Davis, 1989: 320).

\section{Perceived enjoyment}

Enjoyment refers to how much the users enjoy using social media, regardless of the usefulness of the technology (Davis, Bagozzi \& Warshaw, 1992: 1113), while Perceived enjoyment also includes the hedonistic satisfaction of entertainment needs (Van der Heijden, 2004: 696).

\section{Need to belong}

The construct of belonging or the Need to belong is the pervasive human driving force to form and maintain a minimum quantity of lasting, positive and significant interpersonal relationships (Baumeister \& Leary, 1995: 499).

\section{Collective self-esteem}

Collective self-esteem, which is also referred to as social identity in the psychology literature, is that part of an individual's self-concept that emanates from his/her sense of belonging to a social group, as well as the value and emotional importance attached to belonging to that group (Tafjel \& Bruner, 1981: 255).

\section{Need for cognition}

The Need for cognition refers to "the tendency to engage in and enjoy effortful cognitive endeavours" (Cacioppo, Petty \& Kao, 1984: 306).

\section{Dispositional trust}

The propensity to trust or Dispositional trust is the willingness to be dependent on other people in a wide variety of situations (McKnight \& Chervany, 2001: 38).

\section{Interpersonal trust}

Interpersonal trust, in the context of this study, refers to a general trust that a social network user has in the other members of the social network.

\section{Privacy risk}

Privacy risk is the concern for the potential theft of private information (loss of control over possible intrusion), or simply the loss of anonymity and control over personal information (loss of control over disclosure), such as when information is used without knowledge or permission (Featherman \& Pavlou, 2003: 455). Privacy risk includes aspects such as the sharing or selling of personal information, tracking of consumer activities online, placing 'cookies' on browsers, being contacted without consent, and the general invasion of privacy (Miyazaki \& Fernandez, 2001: 28). 


\section{Psychological risk}

Psychological risk reflects the disappointment, sense of foolishness or ego loss (Roselius, 1971: 58), embarrassment, or loss of self-esteem (Mitchell \& Greatorex, 1993: 181), resulting from friends or family knowing that a product or service has failed (Ueltschy, Laroche, Eggert \& Bindl, 2007: 412 ) or that a product or service results in inconsistency with self-image (Chen \& He, 2003: 680).

\section{Social risk}

Social risk refers to the probability that product-usage behaviour will negatively affect the opinion that other people have of an individual. This perception of the views of others is represented by the ego, which is defined as the internal state of self-image control (Chen \& He, 2003: 680). Social risk varies depending on factors such as a product's social importance and its social conspicuousness (Perry \& Hamm, 1969: 352).

\section{Susceptibility to norm influence}

Susceptibility to norm influence refers to the susceptibility of decision-makers towards the influence of reference groups, which are used as standards of comparison for self-appraisal or as a source of personal norms and attitudes.

\section{Internet self-efficacy}

Internet self-efficacy is defined as the belief in one's ability to use motivation, cognitive resources and plans of action in order to satisfy the given demands of a particular situation (Bandura \& Wood, 1989: 229).

This proposed decomposed theory of planned behaviour is graphically depicted in Figure 1.

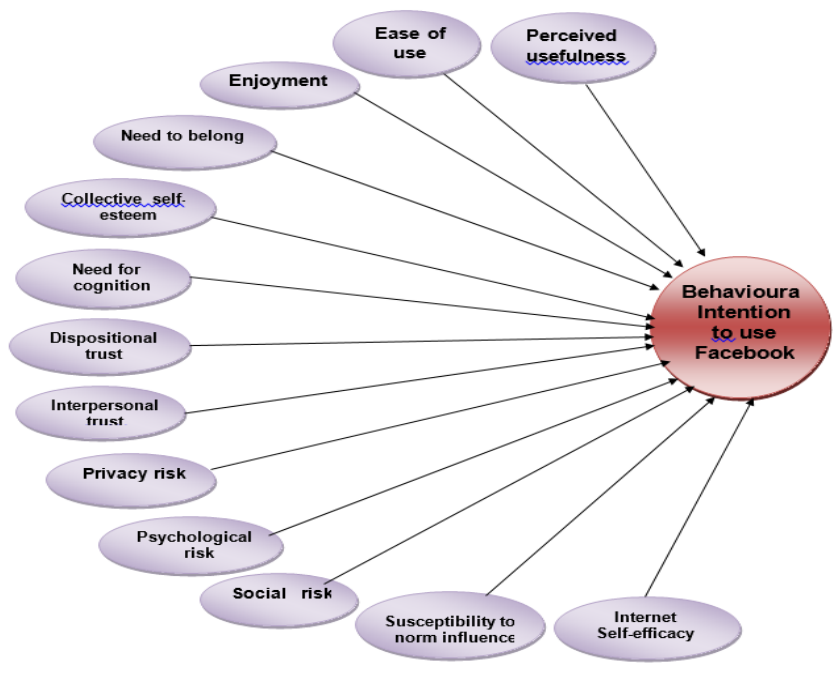

Figure 1 - Decomposed theory of planned behaviour

\section{Barriers and motivators models}

The expanded Theory of Planned Behaviour model contains a large number of factors and, therefore, became too complex to be meaningfully analysed in a single structural equation analysis. A number of authors including Ardichvili (2008: 550) and Ridings, Gefen and Arinze (2006: 332) therefore divide the determinants of user acceptance into two categories, namely motivators and barriers affecting social network users' Continued intention to use social network sites. Motivators refer to factors that have a positive effect on goal-directed behaviour, such as social network usage and barriers are factors that could have a negative influence on social network usage. The factors comprising the expanded Theory of Planned Behaviour model (mentioned earlier) for the users of Facebook, were, therefore, further divided into motivators for and barriers to using social media.

\section{Hypotheses}

The influence of the factors of the decomposed Theory of Planned Behaviour that displayed sufficient convergent and discriminant validity and therefore retained in the final model, were modelled as independent variables and the following hypotheses were addressed:

\section{Barriers to Continued use of social network sites}

H1: Dispositional trust positively influences the continued intention to use social media

H2: Internet self-efficacy positively influences the continued intention to use social media

H3: Privacy risk negatively influences the continued intention to use social media

H4: Psychological risk negatively influences the continued intention to use social media

Motivators of continued social network use for users of social media

H5: The need for cognition positively influences the continued intention to use social media

H6: Perceived ease of use positively influences the continued intention to use social media

H7: Perceived enjoyment positively influences the continued intention to use social media

H8: Perceived usefulness positively influences the continued intention to use social media

H9: Susceptibility to norm influence positively influences the continued intention to use social media 


\section{Methodology}

The target population of the study consisted of the users of the social media website, Facebook, in three main South African cities, namely Johannesburg, Cape Town and Port Elizabeth. Facebook was selected because it is by far the most popular social media site in the world.

As a sampling frame of Facebook users was not available the drawing of a probability sample was thus not possible. A nonprobability multi-method sampling method was therefore used and consisted of both quota and snowball sampling procedures. A quota sampling method was used to ensure that the demographics of the sample represented that of the study population to enhance the validity of the results.

The study utilised a questionnaire with closed-ended questions to collect the demographical information of the respondents. A seven-point Likert scale was selected as the appropriate measurement scale, considering that the variables under investigation were latent and therefore not directly observable. The size of the convenience sample was 307 users of Facebook.

The data were collected both electronically, by means of the completion of the online questionnaire and physically, via the hard copy questionnaire administered by fieldworkers.

\section{Data analysis}

An exploratory factor analysis (principal axis estimation with a direct quartimin oblique rotation) was conducted to assess the discriminant validity of the various constructs in the theoretical model, as proposed by Farrell (2010: 325), using the statistical data analysis programme SPSS 20.0.

The next step was to assess the univariate and multivariate normality of data, followed by assessing the reliability (internal consistency) of each score by using Cronbach's alphas. Additional diagnostics included the average variance extracted (AVE) and an inspection of the squared multiple correlations of indicator variables.

As a result the measurement model was reconstructed and the hypothesised relationships in the structural model were assessed using a structural equation modelling (SEM) approach. The computer programme LISREL 8.80 was used for this analysis. Based on these results, a decision was made regarding the rejection (or not) of the stated hypotheses.

\section{Empirical results}

\section{Validity of the measuring instrument}

An exploratory factor analysis was conducted so that the discriminant validity of the variables could be assessed. This analysis redefined some of the latent variables to be used in the final model for the structural equation modelling, by only including the manifest variables (or items) that loaded to a significant extent and thus demonstrated sufficient evidence of convergent and discriminant validity. The factors affecting the Intention to use or continued intention to use Facebook were regarded as correlated and, therefore, the Principal Axis Factoring with direct quartimin oblique rotation were specified as extraction and rotation methods.

The exploratory factor analysis factor structures are provided in Appendix A. It revealed that the instrument used to measure the latent variables Collective self-esteem (i.e. the emotional significance, derived from the knowledge that the individual is a member of a social group), the Need to belong (i.e. the human driving force to form and maintain a minimum quantity of lasting, positive and significant interpersonal relationships), Interpersonal trust (i.e. the general trust that a social network user has in the other members of the social network) and Social risk (i.e. the probability that a product or service will negatively affect the opinion and reaction other people hold of the individual) did not demonstrate sufficient discriminant and thus construct validity. As a result, these latent variables were removed from the structural (or empirical) model.

The factors that demonstrated sufficient discriminant validity for the Facebook barriers model were: Dispositional trust, Internet self-efficacy, Privacy risk and Psychological risk, while the factors that loaded for the Facebook motivators model were: Need for cognition, Perceived ease of use, Perceived enjoyment, Perceived usefulness and Susceptibility to norm influence.

The results of the reliability and convergent validity assessment of the final model for users of Facebook is presented in Table 1. It reveals that all factor loadings were statistically significant and with one exception, all above 0.6 , offering some evidence of convergent validity. All the scores of the latent variables proved to be reliable, all (except one) returning Cronbach Alpha scores above the generallyaccepted 0.7 cut-off point.

\section{Discriminant validity: Barriers model}

An additional test of the discriminant validity is to compare the average variance extracted for each construct to the squared correlations for each pair of constructs as recommended by Fornell \& Larcker (1981: 123). Table 2 presents a summary of this comparison for the Facebook users barriers model. The results for the barriers of Facebook users indicated that the average variances extracted for each pair of constructs were greater than the squared correlations and, therefore, provided evidence of discriminant validity (Fornell \& Larcker, 1981: 123). The only exception was the relationship between Privacy risk and Psychological risk. However, the difference was very small and both were retained in the model. 
Table 1: Results of the test for reliability and validity assessment of the final model for users of Facebook

\begin{tabular}{|c|c|c|c|c|}
\hline Factors (latent variables) & Item codes & Item loadings & Cronbach's alpha & Average variance extracted (AVE) \\
\hline \multirow{4}{*}{$\begin{array}{l}\text { Dispositional trust } \\
\text { (DT) }\end{array}$} & DT1 & 0.845 & \multirow{4}{*}{0.891} & \multirow{4}{*}{ 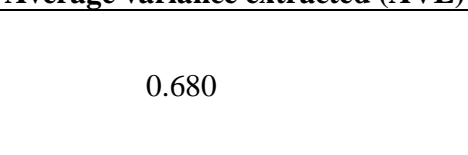 } \\
\hline & DT2 & 0.909 & & \\
\hline & DT3 & 0.775 & & \\
\hline & DT4 & 0.761 & & \\
\hline \multirow{4}{*}{$\begin{array}{l}\text { Ease of use } \\
\text { (EOU) }\end{array}$} & EOU1 & 0.643 & \multirow{4}{*}{0.834} & \multirow{4}{*}{0.565} \\
\hline & EOU3 & 0.789 & & \\
\hline & EOU4 & 0.754 & & \\
\hline & EOU6 & 0.810 & & \\
\hline \multirow{3}{*}{$\begin{array}{l}\text { Internet self-efficacy } \\
\text { (ISE) }\end{array}$} & ISE3 & 0.752 & \multirow{3}{*}{0.742} & \multirow{3}{*}{0.492} \\
\hline & ISE4 & 0.704 & & \\
\hline & ISE5 & 0.644 & & \\
\hline \multirow{3}{*}{$\begin{array}{l}\text { Need for cognition } \\
\text { (NFC) }\end{array}$} & NFC2 & 0.660 & \multirow{3}{*}{0.681} & \multirow{3}{*}{0.418} \\
\hline & NFC3 & 0.622 & & \\
\hline & NFC5 & 0.656 & & \\
\hline \multirow{6}{*}{$\begin{array}{l}\text { Perceived enjoyment } \\
\text { (PE) }\end{array}$} & PE1 & 0.784 & \multirow{6}{*}{0.908} & \multirow{6}{*}{0.637} \\
\hline & PE2 & 0.760 & & \\
\hline & PE3 & 0.775 & & \\
\hline & PE4 & 0.839 & & \\
\hline & PE5 & 0.850 & & \\
\hline & PE6 & 0.740 & & \\
\hline \multirow{4}{*}{$\begin{array}{l}\text { Privacy risk } \\
\text { (PRIV) }\end{array}$} & PRIV1 & 0.675 & \multirow{4}{*}{0.803} & \multirow{4}{*}{0.563} \\
\hline & PRIV4 & 0.712 & & \\
\hline & PRIV5 & 0.803 & & \\
\hline & PRIV6 & 0.654 & & \\
\hline \multirow{3}{*}{$\begin{array}{l}\text { Psychological risk } \\
\text { (PSYC) }\end{array}$} & PSYC3 & 0.771 & \multirow{3}{*}{0.829} & \multirow{3}{*}{0.498} \\
\hline & SOC2 & 0.674 & & \\
\hline & SOC3 & 0.661 & & \\
\hline \multirow{4}{*}{$\begin{array}{l}\text { Perceived usefulness } \\
\text { (PU) }\end{array}$} & PU1 & 0.680 & \multirow{4}{*}{0.824} & \multirow{4}{*}{0.544} \\
\hline & PU2 & 0.662 & & \\
\hline & PU5 & 0.786 & & \\
\hline & PU6 & 0.810 & & \\
\hline \multirow{5}{*}{$\begin{array}{l}\text { Susceptibility to norm influence } \\
\text { (SNI) }\end{array}$} & CSES6 & 0.655 & \multirow{5}{*}{0.845} & \\
\hline & SNI3 & 0.703 & & \\
\hline & SNI4 & 0.795 & & 0.530 \\
\hline & SNI5 & 0.778 & & \\
\hline & SNI6 & 0.701 & & \\
\hline & ITO2 & 0.584 & & \\
\hline & ITO3 & 0.670 & & \\
\hline Continued intention to use & ITO4 & 0.607 & 0.829 & 0.505 \\
\hline & ITO5 & 0.779 & & \\
\hline & ITO6 & 0.873 & & \\
\hline
\end{tabular}

Table 2: Discriminanat validity: barriers model

\begin{tabular}{l|c|c|r|r}
\hline & Dispositional trust & Internet self-efficacy & Privacy Risk & Psychological Risk \\
\hline Dispositional trust & $\mathbf{0 . 6 8 0}$ & & & \\
\hline Internet self-efficacy & 0.036 & $\mathbf{0 . 4 9 2}$ & & \\
\hline Privacy Risk & 0.063 & 0.017 & $\mathbf{0 . 5 6 3}$ & \\
\hline Psychological Risk & 0.048 & 0.006 & 0.513 & $\mathbf{0 . 4 9 8}$ \\
\hline Non
\end{tabular}

Note: AVE in bold and squared correlations below the diagonal

\section{Discriminant validity: Motivators model}

Table 3 presents a summary of the average variance extracted compared to the squared correlations for the Facebook users motivators model. The results for the motivators of Facebook users indicated sufficient evidence of discriminant validity, with the average variances extracted for each pair of constructs being greater than the squared correlations (Fornell \& Larcker, 1981: 123). 
Table 3: Discriminant validity motivators model

\begin{tabular}{l|c|c|c|c|c|}
\hline & Ease of use & $\begin{array}{l}\text { Need for } \\
\text { cognition }\end{array}$ & $\begin{array}{l}\text { Perceived } \\
\text { Enjoyment }\end{array}$ & $\begin{array}{l}\text { Perceived } \\
\text { usefulness }\end{array}$ & $\begin{array}{l}\text { Susceptibility to norm } \\
\text { influence }\end{array}$ \\
\hline Ease of use & $\mathbf{0 . 5 6 5}$ & & & & \\
\hline Need for cognition & 0.086 & $\mathbf{0 . 4 1 8}$ & & & \\
\hline $\begin{array}{l}\text { Perceived } \\
\text { Enjoyment }\end{array}$ & 0.350 & 0.009 & $\mathbf{0 . 6 3 7}$ & & \\
\hline Perceived usefulness & 0.022 & 0.001 & 0.236 & $\mathbf{0 . 5 4 4}$ & \\
\hline $\begin{array}{l}\text { Susceptibility to norm } \\
\text { influence }\end{array}$ & 0.000 & 0.000 & 0.112 & 0.399 & $\mathbf{0 . 5 3 0}$ \\
\hline
\end{tabular}

Note: AVE in bold and squared correlations below the diagonal

\section{Tests for normality of data}

It is important to test for the normality of the data analysed in the structural model, as the analysis is dependent on the normality distribution properties of the data.

As the multi-variate normality assessment confirmed that the data were not normally distributed (skewness and kurtosis chi-square significant), the Robust Maximum Likelihood (RML) estimation method was used to estimate the parameters in the structural model, as recommended by Satorra and Bentler (1994).

\section{Construct validity of the measurement model}

The indices for the Facebook users barriers model confirmed a reasonably close fit with an RMSEA of $0.0511(0.05<$ RMSEA $\leq 0.08$ ) indicating a reasonable fit and CFI a close fit with a value of 0.957 (CFI $>0.95$ indicating a close fit). The $\mathrm{x}^{2} / \mathrm{df}$ score (564.870/314) of 1.799 , was less than 2 and, therefore, also indicated a close fit. The ECVI value was 2.264. The fit indices for the measurement model for the Facebook users motivators model also indicated a reasonably close fit with the RMSEA $($ RMSEA $=0.0614(0.05<$ RMSEA $\leq 0.08)$ showing a reasonable fit, $\mathrm{CFI}=0.961$ ( $>0.95)$ a close fit; $\mathrm{ECVI}=3.676$; and $\mathrm{X}^{2} / \mathrm{df}(966.975 / 449)$ of 2.154 a reasonable fit).

\section{Construct validity of the structural model}

The goodness-of-fit for the barriers model indicated a close goodness- of-fit for all the indices used (RMSEA $=0.0220, \mathrm{CFI}$ $\left.=0.994, \mathrm{ECVI}=0.927 ; \mathrm{X}^{2} / \mathrm{df}(183.591 / 160)=1.147\right)$. The fit indices for the Facebook motivators model also showed a close goodness-of-fit with all indices used (RMSEA $=0.0481(<$ $0.05)$, CFI $=0.979(>0.95) ;$ ECVI $=2.174 ;$ and $\mathrm{X}^{2} / \mathrm{df}$ $(527.355 / 309)$ of 1.707$)$.

\section{Findings and conclusions for barriers of continued Facebook usage}

The primary statistical procedure used to test the hypothesised relationships of the expanded decomposed Theory of Planned Behaviour was structural equation modelling. The findings of the structural equation model for the barriers model revealed a statistically significant positive relationship between: Dispositional trust and continued usage, Internet Self-efficacy and continued usage, and a negative relationship between Psychological risk and continued usage. The relation between Privacy risk and continued Facebook usage was not statistically significant for users of Facebook. The results for the structural model for the Facebook barriers model are illustrated in Figure 2.

\section{Dispositional trust and continued Facebook usage}

The results of the structural model showed a significant $(\mathrm{p}<$ 0.05), positive relationship between Dispositional trust and the Continued intention to use Facebook for users of Facebook (Hypothesis H1 was, therefore, accepted). From the acceptance of $\mathrm{H} 1$, it can be concluded that the more an individual demonstrates a consistent tendency to believe that others are well-meaning and reliable, the more likely they are to use Facebook, which is consistent with findings of studies on user acceptance theory.

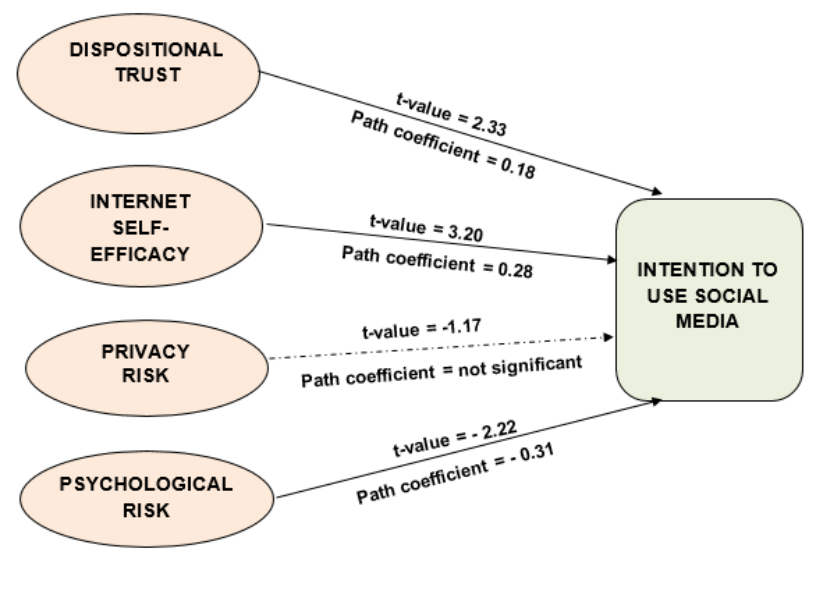

Solid structural paths significant at $p<0.05$

Dashed structural paths not significant at $p<0.05$

Figure 2: Structural model for the Facebook barriers model

This significant positive relationship between Dispositional trust and the Continued intention to use social networks also concur with the findings of Lin (2006: 542), who regards dispositional trust as particularly important in a virtual community environment, because of the lack of formal rules in such a context. Harridge-March, Grabner-Kräuter and Faullant (2008: 489) believe that dispositional trust does not only affect trust towards others, but also towards technical systems and social network sites. The importance of dispositional trust is also evident from the conclusions of Dwyer, Hiltz and Widmeyer (2008: 292) and Muise, 
Christofides and Desmarais (2009: 443) that dispositional trust affects social network usage, because low levels of trust leads to less sharing of information on social network sites. Internet self-efficacy and continued Facebook usage

Internet self-efficacy is the confidence an individual has in their ability to understand, navigate, find, evaluate and contribute information on the Internet, including social network sites such as Facebook.

A significant $(\mathrm{p}<0.05)$ positive relationship between Internet self-efficacy and the Continued intention to use Facebook for users of Facebook was found (Hypothesis H2 was, therefore, accepted). It stands to reason then that the higher an individual's Internet self-efficacy, the more likely they will be to use the Internet and the more they use the Internet, the more likely they are to use Facebook.

This finding is consistent with the findings regarding general internet usage, which suggests that an individual's belief regarding his or her ability and confidence in successfully understanding, evaluating and navigating online content is directly influencing the extent and frequency of Internet usage (Gangadharbatla, 2008: 7). Krämer and Winter (2008: 106) concur that Internet self-efficacy increases social network use and found that Internet self-efficacy influences the level of personal detail provided by users, the number of Facebook friends they have and the style of the user's profile picture on social network sites. Liang, Lai and Ku (2006: 45) found a positive relationship between Internet self-efficacy and technology use among a student population, who were in the age group that used social networks the most.

\section{Privacy risk and continued Facebook usage}

Privacy risk is the concern that users of technology have that their private information will be stolen or that they will lose control over their private information, which could lead to a form of loss, including economic loss, emotional loss or simply a loss of anonymity.

In a social network context, privacy refers to an individual's concern with a loss of control over who has access to his or her personal information and whether the information could be used to his or her detriment. The empirical analysis showed a non-significant relationship between Privacy risk and the Continued intention to use Facebook for users of Facebook (Hypothesis H3 was, therefore, rejected). This finding indicates that Facebook users' concern with privacy does not affect their current social network usage.

Privacy concern has been found to moderate the behaviour of Internet users in most Internet contexts (Ardichvili, 2008; Levin, Foster, West, Nicholson, Hernandez and Cukier 2008: 8; Krasnova, Spiekermann, Koroleva \& Hildebrand, 2010: 109), however, social networking seems to be the exception. Acquisti and Gross (2006: 58) believe there is a disconnect between social networks users' perception of privacy risk and their propensity to make information available about themselves, which the authors refer to as the "privacy paradox". This is evidence that social network users do acknowledge the presence of privacy risk (Ardichvili (2008: 550 ), but do not perceive the risk as either immediate enough or detrimental enough to change their social network usage behaviour. Furthermore, the nature of social networks is to share information, ideas and "cultural artefacts" and therefore, social network users suspend their privacy concerns in a social network context (Boyd, 2007: 134). The privacy concerns associated with social network usage are often voiced by other parties, including the popular press, parents and government institutions, rather than the social network users themselves (George, 2006).

\section{Psychological risk and continued Facebook usage}

Psychological risk is an individual's feeling of disappointment, embarrassment or loss of self-esteem resulting from friends and family knowing that a product or service failed. Psychological risk was found to be significantly $(\mathrm{p}<0.05)$ negatively related to the Continued intention to use Facebook by users of Facebook (Hypothesis H4 was, therefore, accepted).

The negative effects of Psychological risk as a result of social network use were expressed as an erosion of the psychological well-being of a user, and were found to be negatively associated with the positive outcomes of social network use. It can thus be concluded that the more users perceive possible negative effects to arise from social network usage, the less they will tend to use social networks.

These negative effects include sleep deprivation (Fu, Chan, Wong \& Yip, 2010: 486), Facebook depression (Davila, Stroud, Starr, Miller, Yoneda \& Hershenberg, 2009: 909) social isolation, ostracism, social disconnection (Williams, 2007: 427) and so-called 'Cyberostracism' - the latter referring to the sense of exclusion that can sometimes occur in online social environments, (D'Amato, Cecchi, Liccardi, Pellegrino, D'Amato \& Sofia, 2012: 402).

\section{Findings and conclusions for motivators of Facebook usage}

The structural model for the motivators of Facebook usage returned a significant relationship between Perceived enjoyment and Facebook usage and between Perceived usefulness and Facebook usage. A non-significant relationship was found between Perceived ease of use and Facebook usage, between Need for cognition and Facebook usage and between Susceptibility to norm influence and Facebook usage. The results for the structural model for the Facebook motivators model is illustrated in Figure 3. 


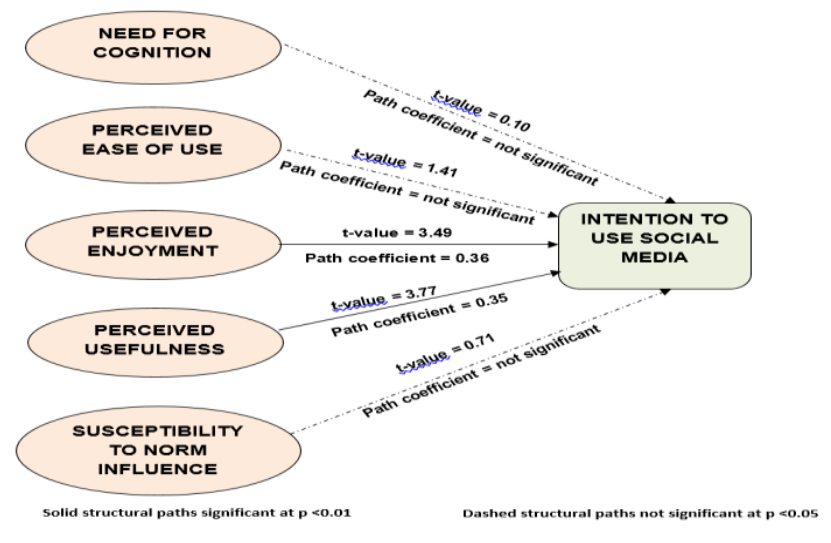

Figure 3 - Structural model for the Facebook users motivators model

\section{Need for cognition and continued Facebook usage}

A non-significant relationship was found between the Need for cognition and the Continued intention to use to use Facebook by users of Facebook (Hypothesis H5 was, therefore, rejected. The literature indicates that people's need for cognition is related to their willingness to use complex systems (Haugtvedt, Petty \& Cacioppo, 1992: 239). All the studies that found a relationship between technology adoption and the need for cognition, however, were conducted in a general Internet context. A study by Gangadharbatla (2008: 7) in a social network site context, concurs with the findings of the current study that Need for cognition did not have any influence on the intention of Internet users to use social network sites

\section{Perceived ease of use and continued Facebook usage}

The extent of mental and physical energy expended to learn a new task or technology is referred to as Perceived ease of use and includes the belief that using a technological system is free of mental or physical effort. The results of the data analysis indicated that the relationship between Perceived ease of use and the Continued intention to use Facebook was not statistically significant (Hypothesis H6 was, therefore, rejected). This rather surprising result indicated that there was no significant relationship between the ease of use and social network usage.

Ease of use is one of the two constructs of the Technology Acceptance Model and, therefore, it was found to affect the acceptance of new technology in many different contexts, including social network sites (Liang et al., 2006:45; Lee \& Suh, 2013:181).

\section{Perceived enjoyment and continued Facebook usage}

Perceived enjoyment, in a social network context, is the intrinsic motivation and hedonistic pleasure, rather than utilitarian purposes, derived from using social networks. The structural equation modelling analysis of the data found a significant $(\mathrm{p}<0.01)$, positive relationship between
Perceived enjoyment and Continued intention to use Facebook by users of Facebook (Hypothesis H7 was, therefore, accepted). Perceived enjoyment refers to the feelings of joy and pleasure associated with a particular act. The positive relationship, therefore, means that the more the use of Facebook is perceived as enjoyable, the more Facebook is used, which is consistent with what has been reported in the literature.

Van der Heijden (2004: 695) suggests that Perceived enjoyment is even more important than usefulness in hedonic systems, with Shin (2007: 472) building on this finding with the assertion that social networks fit the definition of hedonic systems and, therefore, it is expected that Perceived enjoyment will positively affect the use of social networks. In a study by Sledgianowski and Kulviwat (2009: 74) it was concluded that playfulness, which is operationalised similarly to perceived enjoyment, was the strongest determinant of actual social network usage. The finding that enjoyment is a key determinant of social network usage, have also been confirmed by Lin and Lu (2011: 1152).

The literature indicates that Perceived enjoyment is a common motivator for continued social network site usage. Social network sites contain a myriad of games and applications for users to enjoy. The realisation of goals, no matter how small, leads to a sense of achievement, which leads to a feeling of enjoyment, whereas the inability to realise goals leads to frustration and a feeling of internal dissonance and unhappiness. Marketers and social network site developers should ensure that their organisational social network sites continuously add elements for users to enjoy, and that their sites are aesthetically pleasing and easy to navigate. Enjoyable sites will attract new customers and retain existing ones. In other words, useful and informative sites will attract customers, while enjoyable sites retain them.

\section{Perceived usefulness and continued Facebook usage}

Perceived usefulness is the perception of how much a system, such as the social network site Facebook, is able to assist with attaining a goal.

Consistent with the literature, a significant $(\mathrm{p}<0.01)$, positive relationship was found to exist between Perceived usefulness and the Continued intention to use Facebook by users of Facebook (Hypothesis H8 was, therefore, accepted). Perceived usefulness, in a social network context, refers to the degree to which an individual believes that using Facebook would be to his or her benefit. The strong positive relationship between Perceived usefulness and the Continued intention to use Facebook indicates that the more useful Facebook is perceived to be, the higher the user's intentions will be to use Facebook.

The literature relating to perceived usefulness concurs with the conclusions of this study, showing a significant, positive relationship between the perceived usefulness of a social network site and its usage (Lee \& Suh, 2013: 181; 
Sledgianowski \& Kulviwat, 2009: 74; Pfeil, Arjan \& Zaphiris: 653).

\section{Susceptibility to norm influence and continued Facebook usage}

The susceptibility of a decision-maker to the influence of reference groups when making decisions is referred to as Susceptibility to norm influence.

The relationship between Susceptibility to norm influence and the continued intention to use Facebook was found to be not significant and, therefore, Hypothesis H9 was rejected. Susceptibility to norm influence is operationalised as an individual's susceptibility to the influences of reference groups such as friends and family. The non-significant relationship between the Susceptibility to norm influence of users of Facebook and the continued intention to use Facebook indicated that participants were not influenced by reference groups in deciding whether or not to use Facebook.

The finding that susceptibility to norm influence is not related to social network usage is consistent with those of Chow and Chan (2008: 458) as well as Dickinger, Arami \& Meyer (2008: 4). It appears as if, to a large extent, the decision to join and use Facebook is made in isolation without direct influence from reference groups.

\section{Conclusions}

The most important contribution of this study to the body of knowledge relate to the effect of the differential impact of motivators and barriers to the continued intention to use social network sites.

The study further added to the user acceptance literature, by constructing a decomposed model to examine the Intention to continue to use social network sites. This decomposed model is based on the Theory of Planned Behaviour, but is expanded into a comprehensive model, by adding the relevant constructs from the Theory of Reasoned Action, the Technology Acceptance Model, the Motivational Model, the Theory of Planned Behaviour, a model combining the Technology Acceptance Model and the Theory of Planned Behaviour, the Model of Personal Computer Utilisation, the innovation diffusion theory, as well as the Social Cognitive Theory.

This expanded, decomposed model could be further refined in the future and tested and could form the basis of future research as it offers a substantial contribution to user acceptance theory.

\section{Managerial implications}

Several implications flow from the empirical results of this study including the following:

\section{Dispositional trust}

Dispositional trust is intrinsic in nature and is, therefore, difficult for marketers to influence while it is also a construct that changes slowly over time. Dispositional trust forms the basis of building Interpersonal trust, which can be influenced by marketers by constant, transparent communication and the constant benevolent actions of a social network. Another important strategy to develop Dispositional trust over time is promise-keeping without compromise. Branding that emphasises the integrity and reliability of social network sites over time, will add to the Dispositional trust users have in social network sites. Actions without the expressed consent of users (such as the Facebook Beacon programme, where details of user actions were placed on the wall of friends without the users' consent) will reduce Dispositional trust over time and social network site usage will decline.

\section{Internet self-efficacy}

Even though Internet Self-efficacy is also a dispositional construct, marketers and social network site developers can not directly influence this construct. However, marketers and developers can increase the usability of social network sites by keeping the layout simple and adding several different types of online help facilities, such as a searchable help tab, a frequently asked questions (FAQ) section, live assistance, tutorials and demonstration videos.

\section{Psychological risk}

In the context of a social network site like Facebook, where interaction or exposure of personal information is the nature of the medium, embarrassment is a potential consequence of use and, therefore, also a potential barrier to use social network sites. From a marketing perspective, ensuring that a social network site is always available online (never "under construction") and ensuring that the user (as is the case with Internet self-efficacy) has access to a range of help options, will, to some extent, address Psychological risk.

Psychological risk is the perception that significant others have of an individual and, therefore, does have a social aspect to it. However, the impact of the social factors of the expanded model were not statistically significant.

\section{Perceived enjoyment}

The literature reveals that Perceived enjoyment is a common motivator for continued social network site usage. Social network sites contain a myriad of games and applications for users to enjoy. The achievement of goals, no matter how minor, leads to a sense of achievement, which, in turn, leads to a feeling of enjoyment, whereas not being able to realise goals leads to frustration and a feeling of internal dissonance and unhappiness. Marketers and social network site developers need to ensure that their organisational social network sites continuously add elements for users to enjoy and that their sites are aesthetically pleasing and easy to navigate. Enjoyable sites will attract new customers and 
retain existing ones. Useful and informative sites attract consumers while enjoyable sites retain them.

\section{Perceived usefulness}

The strong relationship between Perceived usefulness and continued intention to use social network sites concurs with earlier studies that investigated the specific aspects of social network sites that users found valuable. The fact that users are more likely to utilise social network sites if it is perceived as useful, should indicate to marketers that one of the most important aspects to consider when designing a social network site is to investigate which gratifications social network site users perceive as useful.

\section{Limitations of the study}

Although the study makes a contribution to our understanding of social media usage behaviour it also suffers from a number of limitations. The users of only one social media site (albeit the largest in the world) were surveyed and respondents were not drawn on a random basis, limiting the generalisability of the results. In addition, there is some discriminant validity concerns between the exogenous variables Privacy risk and Psychological risk in the barriers model. These limitations can be addressed in future studies.

A particularly interesting option for future study would be to explore the reasons why so many people, despite the apparent popularity of social media, refuse to be part of its usage.

\section{References}

Acquisti, A. \& Gross, R. 2006. 'Imagined communities: Awareness, information sharing, and privacy on the Facebook', Proceedings of 6th International Workshop of Privacy Enhancing Technologies, 1 January, Berlin, Germany: 36-58.

Ajzen, I. 1991. 'The theory of planned behavior', Organizational behavior and human decision processes, 50(2): 179-211.

Alavi, M. 1984. 'An assessment of the prototyping approach to information systems development', Communications of the Association for Computing Machinery, 27(6): 556-563.

Ardichvili, A. 2008. 'Learning and knowledge sharing in virtual communities of practice: Motivators, barriers, and enablers', Advances in Developing Human Resources, 10(4): 541-554.

Bandura, A. \& Wood, R. 1989. 'Effect of perceived controllability and performance standards on self-regulation of complex decision making', Journal of Personality and Social Psychology, 56(5): 805814.

Barki, H. \& Hartwick, J. 1994. 'Measuring user participation, user involvement, and user attitude', MIS Quarterly, 18(1): 59-82.

Baumann, M. 2006. 'Caught in the web 2.0', Information Today, 23(8):38.

Baumeister, R.F. \& Leary, M.R. 1995. 'The need to belong: Desire for interpersonal attachments as a fundamental human motivation', Psychological Bulletin, 117(3): 497-529.
Boyd, D. 2007. 'Why youth (heart) social network sites: The role of networked publics in teenage social life', MacArthur foundation series on digital learning-Youth, identity, and digital media volume, 119-142.

Boyd, D.M. \& Ellison, N.B. 2008. 'Social network sites: Definition, history and scholarship', Journal of Computer-Mediated Communication, 13(1): 210-230.

Brancheau, J.C., Janz, B.D. \& Wetherbe, J.C. 1996. 'Key issues in information systems management', Management Information Systems Quarterly, 20(2): 225-242.

Cacioppo, J.T., Petty, R.E. \& Kao, C. 1984. 'The efficient assessment of need for cognition', Journal of personality assessment, 48(3): 306-307.

Cha, J. 2010. Factors affecting the frequency and amount of social networking site use: Motivations, perceptions, and privacy concerns [online] URL:http:// firstmonday.org/ojs/index.php/fm/article/ view/2889.

Chen, R. \& He, F. 2003. 'Examination of brand knowledge, perceived risk and consumers' intention to adopt an online retailer', Total Quality Management \& Business Excellence, 14(6): 677-693.

Chow, W.S. \& Chan, L.S. 2008. 'Social network, social trust and shared goals in organizational knowledge sharing', Information \& Management, 45(7): 458-465.

Compeau, D.R. \& Higgins, C.A. 1995. 'Computer self-efficacy: Development of a measure and initial test', Management Information Systems Quarterly, 19(2): 189-211.

Constantinides, E. 2008. 'The empowered customer and the digital myopia', Business Strategy Series, 9(5): 215-223.

Davila, J., Stroud, C.B., Starr, L.R., Miller, M.R., Yoneda, A. \& Hershenberg, R. 2009. 'Romantic and sexual activities, parentadolescent stress, and depressive symptoms among early adolescent girls', Journal of Adolescence, 32(4): 909-924.

Davis, F.D. 1989. 'Perceived usefulness, perceived ease of use, and user acceptance of information technology', Management Information Systems Quarterly, 13(3): 319-340.

Davis, F.D., Bagozzi, R.P. \& Warshaw, P.R. 1992. 'Extrinsic and intrinsic motivation to use computers in the workplace', Journal of Applied Social Psychology, 22(14): 1111-1132.

D'amato, G., Cecchi, L., Liccardi, G., Pellegrino, F., D'amato, M. \& Sofia, M. 2012. 'Social networks: A new source of psychological stress or a way to enhance self-esteem?', Journal of Investigational Allergology and Clinical Immunology, 22(6): 402-405.

Delayco, M.L.C. \& Walcutt, B. 2010. 'Convergence of e-taling and social networking', Summer Internet Proceedings, 12: 128-131.

Desanctis, G. 1983. 'Expectancy theory as an explanation of voluntary use of a decision-support system', Psychological Reports, 52(1): 247-260.

Dickinger, A., Arami, M. \& Meyer, D. 2008. 'The role of perceived enjoyment and social norm in the adoption of technology with network externalities', European Journal of Information Systems, 17(1): 4-11. 
Dillon, A. \& Morris, M.G. 1996. 'User acceptance of new information technology: Theories and models', Journal of the American Society for Information Science, 3: 4-32.

Dwyer, C., Hiltz, S.R. \& Widmeyer, G. 2008. 'Understanding development and usage of social networking sites: The social software performance model', Proceedings of Hawaii International Conference on System Sciences, 41st Annual World Conference, Waikoloa, United States of America, 7-10 January: 292.

Farrell, A.M. 2010. 'Insufficient discriminant validity: A comment on Bove, Pervan, Beatty, and Shiu (2009)', Journal of Business Research, 63(3): 324-327.

Featherman, M. S. \& Pavlou, P. A. 2003. 'Predicting e-services adoption: A perceived risk facets perspective', International Journal of Human-Computer Studies, 59(4): 451-474.

Fornell, C. \& Larcker, D.F. 1981. 'Evaluating structural equation models with unobservable variables and measurement error', Journal of Marketing Research, 18(1): 39-50.

Foster, M.K., Francescucci, A. \& West, B.C. 2010. 'Why users participate in online social networks', International Journal of $e$ Business Management, 4(1): 3-19.

Fu, K.W., Chan, W.S., Wong, P.W. \& Yip, P.S. 2010. 'Internet addiction: Prevalence, discriminant validity and correlates among adolescents in Hong Kong', The British Journal of Psychiatry, 196(6): 486-492.

Gangadharbatla, H. 2008. 'Facebook me: Collective self-esteem, need to belong, and internet self-efficacy as predictors of the iGeneration's attitudes toward social networking sites', Journal of Interactive Advertising, 8(2): 5-15.

George, A. 2006. Living online: The end of privacy? [online] URL: http://www.newscientist. com/channel/tech/mg19125691.700living-online-the-end-of-privacy.html.

Harridge-March, S., Grabner-Kräuter, S. \& Faullant, R. 2008. 'Consumer acceptance of internet banking: The influence of internet trust', International Journal of bank marketing, 26(7): 483-504.

Haugtvedt, C.P., Petty, R.E. \& Cacioppo, J.T. 1992. 'Need for cognition and advertising: Understanding the role of personality variables in consumer behavior', Journal of Consumer Psychology, 1(3): 239-260.

Huber, G.P. 1983. 'Cognitive style as a basis for MIS and DSS designs: Much ado about nothing?', Management Science, 29(5): 567-579.

Ives, B., Olson, M.H. \& Baroudi, J.J. 1983. 'The measurement of user information satisfaction', Communications of the Association for Computing Machinery, 26(10): 785-793.

Karakas, F. 2009. 'Welcome to world 2.0: The new digital ecosystem', Journal of Business Strategy, 30(4): 23-30.

Krämer, N.C. \& Winter, S. 2008. 'Impression management 2.0: The relationship of self-esteem, extraversion, self-efficacy, and selfpresentation within social networking sites', Journal of Media Psychology, 20(3): 106-116.
Krasnova, H., Spiekermann, S., Koroleva, K. \& Hildebrand, T. 2010. 'Online social networks: Why we disclose', Journal of Information Technology, 25(2): 109-125.

Lee, J. \& Suh, E. 2013. 'An empirical study of the factors influencing use of social network service', Pacific Asia Conference on Information Systems, Association for Information Systems, Antlanta, United States, 18 June: 181.

Levin, A., Foster, M., West, B., Nicholson, M.J., Hernandez, T. \& Cukier, W. 2008. The next digital divide: Online social network privacy. Canada: Ryerson University.

Li, C. 2007. Social technographics: Mapping participation in activities forms the foundation of a social strategy. [online]. URL:http://www.forrester.com/Research/Document/Excerpt $/ 0,7211,42057,00$.

Liang, T.P., Lai, H.J. \& Ku, Y.C. 2006. 'Personalized content recommendation and user satisfaction: Theoretical synthesis and empirical findings', Journal of Management Information Systems, 23(3): 45-70.

Lin, H.F. 2006. 'Understanding behavioral intention to participate in virtual communities', Cyberpsychology \& Behavior, 9(5): 540-547.

Lin, H.F. 2008. Predicting consumer intentions to shop online: An empirical test of competing theories', Electronic Commerce Research and Applications, 6(4): 433-442.

Lin, K.Y. \& Lu, H.P. 2011. 'Why people use social networking sites: An empirical study integrating network externalities and motivation theory', Computers in Human Behavior, 27(3): 1152-1161.

Long, M.C. 2013. Social media advertising statistics and trends to get your company off its duff and online. [Online]. URL: http://www.mediabistro.com/alltwitter/social-media-advertisingstatistics_b39349.

Mcknight, D.H. \& Chervany, N.L. 2001. 'Trust and distrust definitions: One bite at a time', Trust in Cyber-societies, 2246(1): 27-54.

Mitchell, V.W. \& Greatorex, M. 1993. 'Risk perception and reduction in the purchase of consumer services', Service Industries Journal, 13(4): 179-200.

Miyazaki, A.D. \& Fernandez, A. 2001. 'Consumer perceptions of privacy and security risks for online shopping', Journal of Consumer Affairs, 35(1): 27-44.

Muise, A., Christofides, E. \& Desmarais, S. 2009. 'More information than you ever wanted: Does Facebook bring out the green-eyed monster of jealousy?', CyberPsychology \& Behavior, 12(4): 441-444.

Perry, M. \& Hamm, B.C. 1969. 'Canonical analysis of relations between socioeconomic risk and personal influence in purchase decisions', Journal of Marketing Research, 6(3): 351-354.

Pfeil, U., Arjan, R. \& Zaphiris, P. 2009. 'Age differences in online social networking-A study of user profiles and the social capital divide among teenagers and older users in MySpace', Computers in Human Behavior, 25(3): 643-654. 
Ridings, C., Gefen, D. \& Arinze, B. 2006. 'Psychological barriers: Lurker and poster motivation and behavior in online communities', Communications of AIS, 18(1): 329-354.

Roselius, T. 1971. 'Consumer rankings of risk reduction methods', The Journal of Marketing, 35(1): 56-61.

Shin, D.H. 2007. 'User acceptance of mobile internet: Implication for convergence technologies', Interacting with Computers, 19(4): $472-483$.

Sledgianowski, D. \& Kulviwat, S. 2009. 'Using social network sites: The effects of playfulness, critical mass and trust in a hedonic context', The Journal of Computer Information Systems, 49(4): 7483 .

Smith, C. By the numbers: 200+ amazing Facebook facts. [online]. URL: http:// expandedramblings.com/index.php/by-the-numbers17-amazing-facebook-stats/.

Sommer, L. 2011. 'The theory of planned behaviour and the impact of past behaviour', International Business \& Economics Research Journal, 10(1): 91-110.

Taylor, S. \& Todd, P. 1995. 'Decomposition and crossover effects in the theory of planned behavior: A study of consumer adoption intentions', International Journal of Research in Marketing, 12(2): 137-155.

Ueltschy, L.C., Laroche, M., Eggert, A. \& Bindl, U. 2007. 'Service quality and satisfaction: An international comparison of professional services perceptions', Journal of Services Marketing, 21(6): 410423.

Urstadt, B. 2008. 'Social networking is not a business', Technology Review, 111(4): 35-43.

Van Der Heijden, H. 2004. 'User acceptance of hedonic information systems', Management Information Systems Quarterly, 28(4): 695704.

Williams, K.D. 2007. 'Ostracism', Psychology, 58(1): 425-452. 